\title{
EL «DISCURSO REPETIDO» COMO MARCA DE CIERRE TEXTUAL EN LA PROSA DE VALLE-INCLÁN 1
}

\author{
Emilio Pastor Platero
}

(Universidad Complutense de Madrid)

\section{INTRODUCCIÓN}

1.1. En diversas investigaciones teórico-literarias recientes se ha insistido en destacar, como una propiedad formal de los discursos literarios, la existencia de diversos mecanismos cuya función específica es delimitar su cierre o su clausura ${ }^{2}$, señalar el término del mensaje (Smith, 1968; Lázaro Carreter, 1980: 149-171; Kermode, 1967; Lotman, 1970, 1973; Greimas, 1970, 1983; Hamon, 1975; Kristeva, 1978: 147-185; García Berrio, 1979; Cohen, 1982: 192; Segre, 1985: 44-45; Kotin Mortimer, 1985; García-Page, 1988: 441-511). De tal manera que se puede entender que

${ }^{\prime}$ Este trabajo se ha realizado merced a una beca predoctoral concedida por la Universidad Complutense de Madrid. Asimismo agradecemos a los profesores J. A. Mayoral y M. Á. Garrido Gallardo sus oportunas sugerencias a una primera versión del mismo.

2 Aunque algunos autores distinguen entre cierre y clausura textual (Hamon, 1975; Kotin Mortimer, 1985; Smith, 1968), en este trabajo se emplearán como términos sinónimos, al no existir diferencia alguna entre ambos vocablos. 
dichos mecanismos son parte importante del proyecto de composición realizado por un autor determinado.

1.1.1. Se puede postular, por tanto, que cualquier emisor puede tener presente un punto en el que su mensaje ha de acabar necesariamente; incluso, se puede entender que este tipo de condicionamiento interno está determinado, en gran medida, por las características del destinatario, en el sentido de que el mensaje se ha podido codificar considerando sus necesidades e intereses (Riffaterre, 1971: 27-63; Senabre, 1987: 11-18), o por las restricciones impuestas por el género discursivo al que pertenece dicho mensaje (García Berrio, 1989).

1.1.2. Sin embargo, es difícil afirmar que exista en un texto dado una serie de recursos destinados, en exclusiva, a marcar el cierre, sino que, por el contrario, es preferible plantear, como principio general, que los procedimientos de estilo que se encuentran más a menudo como marca de clausura pueden encontrarse, a priori, en cualquier lugar del mismo texto (Hamon, 1975: 518). Es decir, que cualquier elemento, sea cual sea su naturaleza, puede constituirse en señal de límite en un texto (García-Page, 1988: 441).

1.2. Otro aspecto interesante de la estrategia compositiva del cierre textual es su importancia apelativa, como llamada de atención al lector y como actualización del contenido informativo aportado en todo un texto, garantizando, a la vez, el carácter permanente, memorizable, propio de cualquier mensaje literal (Lázaro Carreter, 1980: 149-171), y, por ende, de la obra literaria. Quizá haya sido Greimas quien ha destacado, con mayor claridad, esta función del cierre como factor estructurador del mensaje narrativo:

\begin{abstract}
L'originalité des objets «littéraires» (le terme est absolutement impropre) semble pouvoir se définir par une autre particularité de la communication: l'épuisement progressif de l'information, corrélatif du déroulement du discours. Ce phénomène général se trouve systematisé dans le clotûre du discours: celle-ci, arrêtant le flot des informations, donne une nouvelle signification à la redondance, qui, au lieu de constituer une parte d'information, va au contraire valoriser les contenus sélectionnés et clôturés. La clôture transforme donc ici le discours en objet structurel et l'histoire en permanence (Greimas, 1970: 272).
\end{abstract}

1.3. Ahora bien, existe otro problema relativo al estudio de los diversos mecanismos de clausura textual en una(s) obra(s) literaria(s): ¿cuándo y cómo se puede distinguir y afirmar la existencia de un cierre? Si en mensajes literales altamente convencionalizados por la tradición existen fórmulas fijadas para el cierre ${ }^{3}$ — pudiéndose hablar, en definitiva, de clau-

${ }^{3}$ Recuérdese que en la retórica tradicional estaban inventariadas diversas fórmulas fijas en los apartados dedicados al Ars dictaminis, teniendo presente quién era el emisor, quién el receptor y cuál era el mensaje en cuestión (Murphy, 1985: 202-274). 
suras de máxima predicción o sobredeterminadas (Smith 1968: 204)-, no parece que ocurra lo mismo en textos literarios, sobre todo, en los de una amplitud considerable y a priori menos convencionalizados, como puede ser, por ejemplo, la novela. Así, Kotin Mortimer (1985) sólo entiende como fenómeno de clausura el final, en sentido estricto, de una narración, lo que implica, desde su punto de vista, que no puede existir cierre textual en las divisiones en que puede aparecer estructurada una obra. Por otro lado, Culler (1978: 163-178) apela al conocimiento lingüístico-literario del lector, a su competencia literaria, para entender la existencia de un cierre a partir de las convenciones y propiedades presentes y ausentes del texto y su modelo, proponiendo, por lo tanto, un criterio delimitador tan relativo como etéreo. Una postura mucho más formal y más restrictiva es la de Hamon (1975: 507), para quien «[...] il y aura effet de clausure chaque fois qu'il aura perception d'une relation entre parties ou niveaux disjoints d'un même texte». Definición que amplía, sobremanera, el concepto de cierre, pues, por ejemplo, puede postularse, desde este punto de vista, que la transición entre narración y descripción estaría marcada por alguna estructura que señale clausura textual, con lo que una obra tendría innumerables cierres, que el lector no podría identificar siempre.

1.3.1. Es preferible, por tanto, utilizar una concepción intermedia de cierre textual, tal como se considera en Smith (1968) o en Lázaro Carreter (1980), en el sentido de que se podrá hablar de clausura textual cuando el lector o el oyente percibe la existencia de un doble cifrado: 1) el blanco tipográfico en el texto escrito, una pausa muy prolongada en el lenguaje oral; 2) una estructura particular, no necesariamente gramatical, que indica el final del texto. Doble cifrado que refuerza, en el lector, un sentido de integridad y coherencia, de tal forma que se pueda reevaluar el texto positivamente. En cualquier caso, el cierre, aunque, a primera vista, detiene la información aportada en un texto, hace posible, por el contrario, la asimilación y asentamiento de los contenidos recibidos, tiene como misión remitir otra vez al lector sobre la información presente en un texto dado.

1.4. Asimismo, los sistemas de convenciones y códigos empleados para la construcción de un discurso poético permiten plantear que, al igual que cambian los gustos y estilos, priman unas convenciones y se olvidan otras en una época literaria determinada, cabe pensar que los mecanismos de cierre se pueden ir modificando con el paso del tiempo; sobre todo, si vienen implicados por la estructura formal o temática del texto (o modelo) al que pertenecen ${ }^{4}$. Esto es, si está en cierto modo exigido por el conjunto de convenciones practicadas en el acto de cifrado de un texto literario.

${ }^{4}$ Éste es el principio que subyace y se comprueba con numerosos datos en Smith (1968) y en Kotin Mortimer (1985), para el cierre textual en la poesía inglesa y la novela francesa, respectivamente. 
1.5. Es posible, incluso, que en un mismo discurso convivan varios tipos de cierre, dado que debe considerarse como una convención, un mecanismo compositivo del texto artístico (Hamon, 1975). Y cabe pensar que hay autores que privilegian algunas construcciones determinadas para delimitar el cierre en sus textos. Así, en estas páginas trataremos de un recurso determinado: el discurso repetido ${ }^{5}$ (Coseriu, 1977: 113-118) —en adelante abreviado DR - en la obra en prosa de Valle-Inclán ${ }^{6}$. Evidentemente, el DR es sólo uno de los recursos utilizados por Valle para indicar la clausura del texto; si bien, es uno de las más frecuentes, en especial en sus últimas obras.

1.6. Diversos críticos han destacado, con frecuencia, al referirse a la obra de Valle-Inclán, la importancia del DR en su obra, sobre todo la reproducción de canciones o coplas de carácter popular, de textos literarios, más o menos prestigiosos y conocidos, o de citas pertenecientes a la liturgia católica (Díaz-Plaja, 1965; Speratti-Piñero, 1968; Zamora Vicente, 1969; García de la Torre, 1972; Schiavo, 1980; Zavala, 1990). Pero, además, el DR tiene la función de delimitar un cierre, parcial - capítulo-, o total - obra-. De tal modo que se pueden distinguir diversos procedimientos en los que interviene el DR como marca de cierre textual en la prosa de Valle-Inclán:

a) La estructura de cierre no presenta $\mathrm{DR}$, en sentido estricto, sino que el texto se cierra con una alusión a alguna acción o a algún texto que implica la existencia de DR.

b) El texto se cierra con un tipo de DR oral, claramente fijado: saludos, gritos (imprecaciones, insultos, etc.).

c) DR escrito, pero no literario, cuya estructura está claramente fijada (telegramas, tarjetas de visita y similares).

d) DR de carácter literario. Se trata, sobre todo, de la reproducción de coplas populares y de romances de ciego.

1.7. Antes de iniciar el análisis pormenorizado de este recurso, conviene hacer algunas observaciones de carácter general. En primer lugar, nuestra intención es la de estudiar este fenómeno del cierre textual desde un punto de vista estrictamente lingüístico y formal, destacando, sobre todo,

\footnotetext{
${ }^{5}$ Conviene precisar que tomamos el concepto de discurso repetido en un sentido amplio, como la repetición de una mensaje literal ya fijado.

${ }^{6}$ He aquí la relación de obras y sus siglas citadas a lo largo de este trabajo: Sonata de Invierno (SI), Sonata de Primavera (SP), Sonata de Estio (SE), Los Cruzados de la Causa (LCC), Tirano Banderas (TB), La Corte de los Milagros (LCM), Viva mi dueño (VMD). Las citas están tomadas de las ediciones publicadas en la colección Austral de Espasa-Calpe.
} 
los valores de literariedad y de poeticidad (García Berrio, 1979, 1989) que se pueden percibir en el uso del DR como marca de cierre textual. Por otra parte, las conclusiones que de este estudio se puedan desprender, deben considerarse como parciales, al no existir - al menos que sepamos- estudios sobre los mecanismos de cierre textual en la prosa de autores coetáneos, anteriores o posteriores a Valle-Inclán ${ }^{7}$. En último lugar, advertimos, otra vez, que tratamos sólo de un recurso determinado - el DR-, pero que el cierre textual en la prosa de Valle-Inclán puede estar representado por diversas estructuras, con variados valores gramaticales, semánticos y pragmáticos, que, sin duda, son merecedores de un estudio detallado.

\section{DR IMPLÍCITO}

2.1. Un primer procedimiento detectable en el uso del DR como clausura del texto en la prosa de Valle-Inclán consiste en la alusión a una actividad que suponga la aparición del DR sin que sea citado de modo explícito en el texto. El lector, por tanto, puede entender y llenar ese punto de indeterminación con un $\mathrm{DR}$ determinado. Uno de los recursos más frecuentes, sobre todo en las Sonatas, es el de clausurar un texto con una indicación del narrador de que uno o varios de los personajes presentes en la secuencia rezan, procedimiento derivado de una de las isotopías genéricas dominantes (Greimas, 1970; Rastier, 1973, 1987) en las Memorias de Bradomín, que refiere directamente al ambiente religioso en el que se mueve el narrador autobiográfico y sus respectivas amadas:

1.a) La Niña Chole alzó la voz, rezando en acción de gracias por nuestra venturosa jornada. Los siervos respondian a coro. Yo como caballero santiaguista recé mis oraciones dispensado de arrodillarme por el fuero que tenemos de canónigos agustinos (SE, $122[11])^{8}$.

1.b) Avizarado miraba alternativamente a la puerta y a la gran reja de la sacristia. Seguimos su prudente consejo, y mientras nosotros platicábamos retirados en un extremo de la sacristía, en el otro rezaba medrosamente la Niña Chole (SE, $138[17])$.

1.c) El comandante hizo abrir la puerta y entraron en la iglesia. Moviendo las linternas se dispersaron por las capillas, y varias veces fueron y vinieron del presbiterio al cancel, y pasaron y repasaron de una nave a otra nave. Alzaban

\footnotetext{
${ }^{7}$ La única monografia española en que se trata este asunto con pormenor es en la tesis doctoral de M. García-Page (García-Page, 1988: 439-511).

${ }^{8}$ Además de citar obra y página, nos ha parecido conveniente añadir entre corchetes la parte, el libro, si ha lugar, y el capitulo que se cierra con el ejemplo citado.
} 
los paños de los altares y abrían los confesionarios. En el coro, las sombras de las monjas cantaban su latin (LCC, 59 [12]).

2.2. Este recurso de cerrar un texto determinado señalando que algún(os) personaje(s) realiza(n) un acto de enunciación, que implica la existencia de un DR altamente codificado - oraciones--, permite al narrador dejar en suspenso al enunciador de ese DR. Por otra parte, es, asimismo, interesante señalar que este tipo de cierre se emplea con indudable frecuencia para contraponer la posición o la actitud de unos personajes frente a otros, en un cuadro determinado. En (1a), si bien todos los participantes rezan, se distribuyen en dos grupos: por un lado, la Niña Chole y el cortejo que la acompaña, $y$, por el otro, Bradomín, distinguido por su posición en el momento de rezar (dispensado de arrodillarme), e, incluso, por el tipo de rezo, de DR que enuncia (mis oraciones, en vez del rezando de la Niña Chole). Frente al gerundio empleado para señalar la acción efectuada por la Niña Chole, el DR-oración de Bradomín se individualiza por el posesivo destacado por el narrador.

2.2.1. En (1b), el contraste se explicita con mayor claridad, al distinguirse entre la que enuncia el DR-rezo, otra vez la Niña Chole, y Bradomín y Fray Lope, que no lo realizan. Más clara aún es la contraposición efectuada en el cierre presente en (1c), al oponer la actividad del registro que llevan a cabo en el convento las tropas isabelinas, frente a las monjas que rezan. Se contrapone la actividad frenética de las tropas (marcada por la sucesión de verbos en pretérito indefinido, en algún caso de significado contrapuesto, junto con el empleo del polisíndeton) y el estatismo de las monjas (marcado por un único verbo, que indica enunciación de DR, en pretérito imperfecto). Por otra parte, la acción de enunciar DR está sugerida con gran fuerza por medio de la construcción gramatical constituida por $\mathrm{V}+\mathrm{SN}$, en la que ambos elementos indican la enunciación de un tipo de DR determinado: cantaban su latín.

2.3. Otro subtipo de este procedimiento de cierre consiste en que el narrador o algún personaje haga mención a una clase de discurso interpretable como DR:

2.a) El prelado recogióse los hábitos con empaque doctoral, y en ese tono agresivo y sonriente, que suelen adoptar los teólogos en las controversias de los seminarios, comenzó un largo sermón (SI, 170 [24]).

2.b) - Hermana, ¿ha reparado qué inocente corazón? Tiene la simplicidad de aquella lega cuya historia refiere nuestra Madre Santa Clara (LCC, 99 [21]).

2.c) Del Coto de los Carvajales quedan luengas memorias en las páginas tontainas de Asmodeo (LCM, $84[4,1]$ ). 
2.d) El Infante de Orleáns [sic], zamacuco y burgués con la pluma en la oreja, repasa sus libros comerciales y suspira el tango cañi del Adiós mi Dinero (VMD, $15[1,9])$.

2.3.1. En (2a) y (2b) se mantiene la referencia a la enunciación de un DR de carácter marcadamente religioso, si bien su valor es de diversa índole. En (2a) el acto de enunciación del DR que sirve de cierre textual - comenzó un largo sermón - está matizado por las diversas oraciones que le preceden, que señalan la acción del clérigo en el momento de iniciar su discurso, y el tono, la voz con que va a pronunciarlo. Por otro lado, es interesante reparar en el uso del deíctico ese para determinar el tono del prelado, que intenta relacionar la acción narrada con la experiencia ordinaria del lector (Lázaro Carreter, 1990:161). Y esta referencia a lo cotidiano de lector se matiza y amplía por medio de una oración de relativo, que, además de un valor rítmico característico (Beccaria, 1964, 1975), explica con calma retardadora en qué consiste ese tono peculiar que Bradomín atribuye al prelado.

2.3.2. En (2b) la alusión a un tipo de DR determinado (una historia piadosa, o una hagiografía) aparece como comentario a una acción realizada por una de las novicias, que permite al personaje referir el parecido de la novicia con un personaje de un DR determinado. Es decir, la acción permite a un personaje clausurar el texto con la identificación entre esa acción y un tipo específico de DR.

2.3.3. En (2c) la alusión al DR tiene una función específica de marco (Lotman, 1973), en la que el narrador cierra la descripción de un lugar determinado - el Coto de los Carvajales-, con una indicación a un DR en el que se puede conseguir más información acerca del lugar que se ha descrito. Pero, a la vez, se califica negativamente - páginas tontainas - al $\mathrm{DR}$ al que se remite.

2.3.4. En (2d) se repite el procedimiento de cerrar un texto por medio de presentar a un personaje enunciando un DR determinado, una canción, pero al narrador le basta con citar el título del tango, para esperar que la descodificación del lector sea la correcta, y pueda rellenar ese punto de indeterminación con toda facilidad.

\section{CIERRE TEXTUAL CON DR, EN SENTIDO ESTRICTO}

3.1. La segunda clase de cierre textual que distinguimos consiste en que el DR en cuestión se presenta como propio, pero no exclusivo, de la comunicación coloquial y es de breve extensión. Consiste en marcar el fin de un texto por medio de locuciones, fijadas por el uso [i. e., DR en sentido 
estricto, según la concepción de Coseriu (1977)], que reproducen fórmulas estereotipadas, convencionalizadas al máximo, tales como saludos, frases en latín de la liturgia católica, gritos (en especial los que tienen que ver con la venta de algo, sobre todo, periódicos) y formas similares.

3.2. En primer lugar tenemos diversos ejemplos de cierre textual en que aparece este tipo de DR:

3.a) Su voz era lastimera, resignada, llena de penas. Verdadera voz de siervo. No le dolía el engaño por la afrenta de hacerle cornudo, sino por la baja elección que la tehuana hacía: Era celoso intermitente, como ocurre con la gente cortesana que medra de sus mujeres. El duque de Saint-Simon le hubiera loado en sus Memorias, con aquel delicado y filosófico juicio que muestra hablando de España, cuando se desvanece en un éxtasis, ante el contenido moral de estas dos palabras tan castizas: Cornudo Consentido (SE, 155 [24]).

3.b) Todos se inclinaron como si yo fuese el Santo. El temblor de un rezo pasó por las luengas barbas, que salían del misterio de las capuchas, y en aquel momento yo sentí el deseo de arrodillarse y besar la mano del Prior. Aquella mano que sobre todos mis pecados podia hacer la cruz: Ego te Absolvo (SP, 44 [10]).

3.c) Me contaron que ahora, al cabo de treinta años, ya repite sin pasión, sin duelo, con la monotonía de una vieja que reza: ¡Fue Satanás! (SP, 92 [28]).

3.2.1. Este recurso de cierre viene a ser una ampliación, $\mathbf{0}$, incluso, una variante de los casos citados en (1) y (2), pues presenta un acto de enunciación que implica la existencia de DR - (3b), (3c)—o alude a algún tipo de DR - (3a) - , para, inmediatamente, añadir el DR basado en alguna fórmula estereotipada. En (3a), el cierre, que aparece en el texto para calificar la voz y la actitud del personaje, va preparándose por medio de la alusión a un autor (duque de Saint-Simon) y un texto (sus Memorias), presentados como conocidos por la competencia del lector, para introducir el DR consistente en una locución claramente estereotipada.

3.2.2. En (3c) el cierre (el grito de $\mathrm{M}^{\mathrm{a}}{ }^{\mathrm{a}}$ Rosario) aparece caracterizado como DR por medio de un verbo dicendi que lo introduce (rezar). Un verbo que implica la fuerte convencionalización del DR, además de añadir la isotopía religiosa que impone al discurso directo del personaje. Al mismo tiempo, esta frase se identifica como DR por la iterabilidad que le otorga el narrador - al cabo de tantos años, ya repite-, con lo que se sugiere que la frase de M. ${ }^{a}$ Rosario, si pudo ser innovación en su momento, ha pasado a ser un cliché, un DR, por efecto de la reiteración.

3.3. Un segundo aspecto de este cierre textual por medio de este tipo de DR es el empleo de gritos, emitidos por un grupo de personajes (Sobejano, 1988), muy convencionalizados, en los que pueden distinguirse dos clases: voces a favor o en contra de algo o de alguien y gritos de vendedores 
anunciando su mercancía. En primer lugar están los ejemplos de gritos a favor o en contra, formados a partir de Viva/Muera $+S N$ :

4.a) Como en los siglos medioevales y religiosos llegaban desde la calle las voces del pueblo: ¡Viva Dios! ¡Viva el Rey! (SI, 147 [17]).

4.b) Sucesivos grupos con banderas y bengalas, aplausos y amotinados clamores, a modo de reto, gritaban frente al Casino Español:

- iViva Don Roque Cepeda!

- iViva el libertador del indio!

-Vivaaa!...

- iMuera la tirania!

- iMuera!...

- iMueran los gachupines!

- iMueran!... (TB, 67 [2,1,4].

4.c) Y la pelazón de indios seguía gritando en torno de los faroles que anunciaban el mitin:

-iMuera el Tío Sam!

- Mueran los gachupines!

-iMuera el gringo chingado! (TB, 67 [2,1,4]).

3.3.1. Este cierre textual por medio de DR constituido por gritos, cuya expresión está claramente prefijada, aparece como procedimiento agrupador de personajes episódicos en una escena determinada, enmarcando la entrada de las tropas carlistas (4a), o el discurso de Roque Cepeda, que antecede la revuelta en Tierra Caliente contra el Tirano (4b-c).

3.3.2. El segundo tipo de cierre textual formado por un DR que expresa un grito consiste en la reproducción de voces de vendedores. Si en casos anteriores la clausura por DR dejaba a los diversos personajes en suspenso, realizando algún acto de enunciación, en estos ejemplos las voces de los vendedores pregonando su mercancía aparece como un marco (Lotman, 1970, 1973), como un cierre en sentido estricto, al haber concluido la acción realizada por algún(os) del/los personaje(s) principal(es). Es decir, una vez acabada esa acción, se pasa a dar una pincelada ambiental de carácter más amplio y general, por la alusión a voces, no a personas, con lo que el texto se cierra, con un mensaje oral que difumina el decorado en el que se desarrolla la acción:

5.a) Tras la tapia cubierta de yedra, pasa pregonera una voz: ${ }_{i}$ Cribos! ‘Cribos!... ¡Cedazos buenos!... iPara la harina de maiz, para harina de centeno! ¡Cribos, cedazos y arneros! (LCC, 148 [32]).

5.b) Runflaba la locomotora, y la ringla de mujerucas levantaba sus cacharros ibéricos a lo largo del andén: ${ }_{i}$ El botijo tres cuartos! ¡Fresca! ¡Fresca! (LCM, $180[8,1])$. 
5.c) Metían en competencia sus trinos, una mujerona desfondada y un mangante con mal de orzuelos: - iExtraordinario de La Correspondencia! iGravedad del Duque de Valencia! (LCM, $191[8,8])$.

3.3.2.1. Es, asimismo, interesante señalar el intenso ritmo marcado por estos gritos, combinado - en (5a) - con una similicadencia en las tres últimas exclamaciones, que determinan con mayor claridad el fuerte valor fónico y rítmico de este DR.

3.3.2.1.2. El grito de vendedores como marca de cierre en $(5 \mathrm{c})$ presenta una característica peculiar con respecto a los anteriores ejemplos: lo que se vocea es un periódico. El DR está formado por la reproducción de un mensaje oral, pero que tiene como base un mensaje escrito -el titular de ese periódico--, con lo que podría pensarse que ocupa un lugar intermedio entre el cierre textual reflejado en (5) y los que vamos a tratar a continuación en los que el DR tiene origen textual.

\section{CIERRE POR DR ESCRITO NO LITERARIO}

4.1. Un tercer procedimiento de clausura textual por medio de DR en la prosa de Valle-Inclán consiste en la reproducción de un texto escrito, no literario y muy convencionalizado. Se trata, en estos casos, de cerrar el texto con la cita de tarjetas de visita, telegramas y mensajes literales similares. Por medio de esta clausura textual se consiguen efectos propios de la novela por entregas, al cerrarse un capítulo o una parte de una novela con la presentación de un personaje - tarjeta de visita - o con el resumen de una acción, conocida o no por el lector - telegrama-, con lo que se insiste en algún aspecto anterior del relato que el lector debe interpretar como importante para el desarrollo de la trama:

6.a) En lo más florido de mis años hubiera dado gustoso todas las glorias mundanas por poder escribir en mis tarjetas: El Marqués de Bradomín, Confesor de Princesas (SP, $61[16])$.

6.b) El suceso, troquelado con el estilo epigráfico y lacónico del cable, rodó por los grandes periódicos del mundo: «Santa Fe de Tierra Firme. El Honorable Cuerpo Diplomático acordó la presentación de una nota al Gobierno de la república. La nota, a la cual se atribuye gran importancia, aconseja el cierre de los expendios de bebidas y exige el refuerzo de guardias en las Legaciones y Bancos Extranjeros» (TB, $211[6,3,4])$.

6.c) Tocaron en la puerta. El lacayo de estrados presentaba un telegrama en bandeja de plata. El Marqués, luego de abrirlo, quedó alelado. Volvió a leer: - Guar- 
dias buscan Segismundo. Lleváronse Tio Juanes. Horrores. Llegaremos mañana. Carolina (LCM, $196[8,11])$.

6.d) Por mucho menos dinero, el apóstol de la fraternidad ofrecía el cismático papel a la revolución española: Mostraba una tarjeta de visita: El teniente Coronel.Felipe Solis y Angulo.-Ayudante de S.A.R. el Serenísimo.- Señor Duque de Montpensier (VMD, $234[9,4])$.

4.1.1. Hay algunas diferencias en los ejemplos agrupados en (6). En (6a), la alusión a la tarjeta de visita es una parte de un párrafo que, en su totalidad, sirve como cierre, y desarrolla, al mismo tiempo un comentario de Bradomín-narrador a un aspecto determinado de la acción ${ }^{9}$.

4.1.2. En el resto de los casos, el DR tiene como función la de resumir una acción, incluso reenviando a lo narrado con anterioridad - $(6 \mathrm{c})-$, para resaltar el efecto que produce esa acción en otros personajes. En (6b) la reproducción de la nota de prensa sirve como clausura de la reunión de los embajadores extranjeros en Tierra Caliente, tratada por Valle-Inclán con enorme dureza degradadora, que, a su vez, cierra el libro sexto de TB, inmediatamente anterior a la revuelta contra Santos Banderas. De tal modo que este DR anticipa lo que va a ocurrir en la novela, destacando, asimismo, la actitud de la legación extranjera ante estos hechos, marcada, en especial, por el consejo del cierre de los expendios de bebidas. En (6c), el DR reproduce un telegrama que resume y reenvía al lector a una acción ya narrada, resaltando la sorpresa de Torre-Mellada. Mientras que, en (6d), el DR representado por la tarjeta de visita introduce en el relato a Bakunin (el apóstol de la fraternidad), dando al lector, además, la información de su entrada con papeles falsos.

\section{CIERRE TEXTUAL POR DR LITERARIO}

5.1. El siguiente procedimiento de clausura textual por medio de la utilización de DR es el más usual en la prosa de Valle-Inclán, y aparece, sobre todo, en sus últimas obras. Dicho recurso consiste en cerrar un texto por medio de un DR representativo de discurso literario. Y se puede manifestar, al menos, de tres maneras: a) cita de poemas marcados como literarios; b) cita de cantares populares, de carácter festivo o con cierto contenido político; y c) variante del caso anterior, cita de un romance de ciego, que tiene relación con la acción narrada a la que sirve de clausura.

${ }^{9}$ Este paso de Bradomín-personaje a Bradomín-narrador tiene un procedimiento característico en el empleo del epifonema en la prosa de las Sonatas (Pastor Platero, en prensa). 
Se trataría de una construcción que podría considerarse como especular (Dällenbach, 1977).

5.2. El primer subtipo que puede distinguirse en este apartado de DR literario consiste en que el texto se cierra con la alusión de algún poema caracterizado, en mayor o menor medida, como literario:

7.a) $\mathrm{Y}$ en la sombra del foque abría su lírico floripondio de ceceles el negro catedrático:

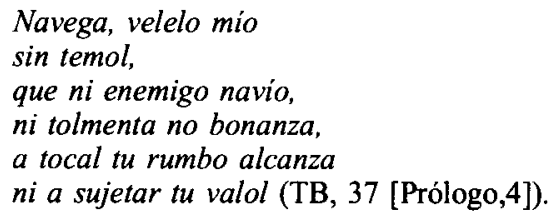

7.b) El fácil poeta de las gacetillas brinda una letra. Improvisados coros la dan al viento:

- ¿Una España con honra queremos,

y que invictos decoren su sien los laureles de Otumba y Pavia, de Sagunto y Numancia también!

La música sale por los balcones y recorre las aceras, saltando sobre los mecheros del gas que alumbraban de repente (VMD, $162[6,9])$.

7.c) La vena gacetillera ha dejado en la métrica de ocho versos la moraleja de Don Augusto Ulloa:

Sin más letras que el Catón

este gallego lucense

pasa por otro Brocense

en el seno de la Unión.

Con pieles en el gabán,

mucha voz y mucha panza.

en la Villa y Corte alcanza

fama cualquier charlatán (VMD, 164 [6,10]).

5.2.1. Lo primero que cabe comentar sobre este DR es la marcada intención paródica que tiene la aparición de dicho DR, bien por la reproducción de un poema conocido (7a): la Canción del Pirata de Espronceda, pero recitado por un personaje episódico al que se le caracteriza por un defecto en su pronunciación (confunde $r$ con $l$ ), que marca grotescamente el recitado; o bien por el mismo contenido de los poemas empleados como marca de cierre textual $(7 b, 7 c)$.

5.2.2. Por otro lado, es interesante señalar que, en estos dos últimos ejemplos, se atribuye la creación del DR a poetas gacetilleros, representantivos de la tradición poética grandilocuente (7b) o de la festiva (7c) del siglo XIX, pero siempre con una clara intención paródica, resaltando, sobre todo en (7b), la gran difusión de estos textos. 
5.3. El segundo subtipo que podemos distinguir en la aparición del DR de carácter literario en la prosa de Valle-Inclán, como señal de clausura textual, consiste en la reproducción de coplas populares y de cantares de ciego. En este caso pueden distinguirse, como señalábamos con anterioridad, dos grupos: el cierre se logra con el empleo de coplas de carácter lúdico, o se consigue por medio de cantares de signo político, sobre todo, anti-isabelinos.

5.3.1. Ejemplos del primer caso, son, entre otros:

8.a) En la calle rasgueaban guitarras y se oía el paso de una rondalla que desfilaba bajo los balcones del palacio, cantando a voz en cuello:
iLa trincadura Almanzora
todo lo tiene de bueno:
El Comandante rumboso,
la gente muycho salero! (LCC, 44 [8]).

8.b) La bisoja recogió la pellejuela y, levantándola con garbo, refrescóse la boca. Luego, sacando una tajada el lebrillo, se puso a cantar:

- iAquel tuno, tuno,

robarme quería,

robarme la cerda

que llevo en la liga! (LCM, $111[5,7])$.

8.c) El vejete de la cama vecina, con el sol en las gafas, estudia el remiendo y anuda la hebra, embebido en una canturia de turulato:

- iBueno, bueno, bueno!

¡Se casó Moreno!

¿Malo, malo, malo!

¡Mató a su mujer de un palo! (VMD, 195 [7, 13]).

En los casos citados en (8), el cierre por medio de esta clase de DR tiene una estricta función de marco de la acción, pues no se deja a los personajes en suspenso, efectuando alguna actividad, sino que se destaca, como ocurría en los casos citados de los gritos como recurso para clausurar un texto, a un personaje episódico, que tiene como única función introducir el cantar popular con el que se cierra el texto.

5.3.2. Similar es el procedimiento cuando el DR contiene canciones, más o menos populares, de contenido político. En estos casos, lo que cambia es el significado presente en el DR, pues ya no indica, como en (8), canciones de carácter popular, sino que se alude a textos contrarios a la Reina Isabel II y a su política, recurso en consonancia con los hecho relatados en El Ruedo Ibérico. En todos los casos el DR está introducido por un personaje anecdótico para el desarrollo de la acción, siendo presentado en ocasiones, no como una persona, sino como una voz: 
9.a) Los marineros seguían bailando, cogidos de los hombros. El de la voz ceceosa, rasgueando sobre el fusil como si fuese una guitarra, comenzó a cantar:
iIsabel y Marfori,
Patrocinio y Claret,
para formar un banco,
vaya unos cuatro pies! (LCC, 56 [11]).

9.b) Si en el silencio de la medianoche oían [las monjas] el punteado de las rondallas, deslizábanse, furtivas y descalzas, de sus catres penitentes, para acechar, como novias, tras de las rejas:

- Levantaremos pendones,

por la Santa Religión,

que nos sobran los riñones

a los hijos de Aragón (LCM, 16 [1,10]).

9.c) [...] Rasguea el dómine:

- Pro causa naturae,

el padre Claret

una bula obtuvo

para la Isabel ... (VMD, $23[1,19])$.

5.4. El último procedimiento con el que Valle-Inclán utiliza un DR de carácter literario como marca de cierre textual es una variante de los ejemplos anteriores, con la particularidad de que el romance de ciego con el que se clausura el texto va evolucionando según evoluciona el relato, $\mathrm{y}$, además, lo que se canta en el DR-cierre del texto es un reflejo de lo que ocurre o va a ocurrir en la narración principal. Valle-Inclán lo utiliza, al menos, en dos ocasiones.

5.4.1. La primera de ellas, en TB, relaciona el romance de Diego Pedernales con la peripecia y detención del Licenciado Veguillas, dentro del texto principal, es decir, se produce una relación narrativa de tipo especular (Dällenbach, 1977):

10.a) La voz del ciego desgarraba el calino silencio:

-Era Diego Pedernales

de noble generación,

pero las obligaciones

de su sangre no siguió $(\mathrm{TB}, 49[1,1,8])$.

10.b) En los portalitos, por las pulperías de cholos y lepes, la guitarra rasguea los corridos de milagros y ladrones:

Era Diego Pedernales

de buena generación (TB, 89-90 [3,1,1]).

10.c) La sombra de la mano, con el reflejo de las tumbagas, pone rasgueo de luces en el rasgueo de la guitarra:

Preso le llevan los guardias,

sobre caballo pelón.

que en los Ranchos de Valdivia

le tomaron a traición. 


\section{Celos de niña ranchera}

hicieron la delación (TB, 91-92, [3,1,3,]).

La copla alusiva a Diego Pedernales cierra, al principio de TB, diversas series descriptivas, que, en apariencia, no establecen ninguna relación fuerte entre marco-cierre y texto. Pero, a la vez, este DR anticipa el prendimiento de Nachito Veguillas y las causas que lo originarán. Es de notar que el corrido, el DR, continúa, en el interior del relato, marcando, con la misma claridad, el resto de la peripecia vital del Licenciado. De tal manera que cuando Veguillas muere en TB, desaparece el romance de ciego, no sin indicar, antes, la muerte de Diego Pedernales.

5.4.2. Un fenómeno similar, aunque, tal vez, menos logrado, se produce en VMD con el romance de ciego sobre el crimen de la Solana, el cual aparece como marca de clausura textual, para relacionar el crimen cantado en el DR con la caída de Torre-Mellada:

11.a) En la escalinata, un ciego romancista recuenta los pliegos del Horroroso Crimen de Solana. Los leones, duales y contrarios, esperezan un regaño simétrico. - ¿La más culpada de todos,

una mujer ha salido!

Oprobio del bello sexo, por sus perversos instintos, a las inocentes victimas sacaba los higadillos... (VMD, $88[4,3]$ ).

11.b) Guitarra y solfa. Rondas de morapio. Apolo cuelga su laurel en la puerta de un ventorrillo. Desafina el ciego:

iEn un negro calabozo,

confesados y convictos pagan su sanguinidad los malvados asesinos! Piden indulto al Gobierno el clero y el municipio, militares y paisanos, viejos, mujeres y niños (VMD, 215-216 [8,8]).

11.c) A la puerta del tabernucho, en una rueda de avinados fervores, enronquecía el ciego, al compás del guitarro:

La más culpada de todos una mujer ha salido; a las inocentes victimas sacaba los higadillos, y guisados se los daba de cena a los asesinos (VMD, $219[8,10])$.

Al igual que ocurría con el corrido de Diego Pedernales y su reflejo en TB, también en el romance del crimen de la Solana, el DR pasa de tener 
como función marcar clausura textual a insertarse en la narración principal, mostrando, así, con mayor fuerza, la relación establecida entre el DR y la caída en desgracia de Torre-Mellada en VMD.

\section{CONCLUSIÓN}

Hemos tratado de estudiar en este trabajo las diversas variantes de un procedimiento que se puede encontrar, con cierta frecuencia, en la prosa de Valle-Inclán: el cierre textual efectuado por medio del DR. Es evidente que este recurso aumenta en sus últimas obras, dado que en ellas crece en número y en calidad no sólo la presencia de DR, sino el diálogo en general. Con todo, como hemos advertido al principio de estas páginas, sólo se pueden extraer conclusiones parciales, al no existir trabajos acerca de los diversos mecanismos utilizados por Valle para clausurar un texto. Así, sin salir de este autor, sería interesante tratar de otros recursos, como, por ejemplo, los comentarios que el narrador hace acerca de lo narrado (muy frecuente en las Sonatas), la manera de concluir una serie descriptiva en posición final de texto por medio de una frase-resumen, el diálogo (no repetido), y otros que sería prolijo enumerar. Con todo, tal vez estos datos que aportamos con este estudio puedan incitar a alguien a estudiar con mayor profundidad un campo virgen, pero apasionante, como es este de la clausura textual.

\section{Referencias bibliográficas}

BECCARIA, G. L. (1964): Ritmo e melodia nella prosa italiana. Studi e ricerche sulla prosa d'arte. Florencia: Leo S. Olschik.

- (1975): L'Autonomia del Significante. Turín: Guilio Einaudi.

CoHEN, J. (1982): El lenguaje de la poesía. Teoría de la poeticidad. Madrid: Gredos. CoSERIU, E. (1977): Principios de semántica estructural. Madrid: Gredos.

CulleR, J. (1978): La poética estructuralista. Barcelona: Anagrama.

DÄLlENBACH, L. (1977): Le récit speculaire. París: Seuil.

Díaz-PlAJA, G. (1965): Las estéticas de Valle-Inclán. Madrid: Gredos.

García Berrio, A. (1979): «Lingüística, Literariedad/Poeticidad (Gramática, Pragmática, Texto)». $16162,125-170$.

- (1989): Teoria de la Literatura. Madrid: Cátedra.

GARCíA DE LA TORRE, J. M. (1972): Análisis temático del Ruedo Ibérico. Madrid: Gredos. 
GARCíA-PAGE, M. (1988): La lengua poética de Gloria Fuertes. Madrid: Universidad Complutense.

Greimas, A. J. (1970): Du Sens. Essais Sémiotiques. París: Seuil.

- (1983): La semiótica del texto. Ejercicios prácticos. Barcelona: Paidós.

HAMON, Ph. (1975): «Clausules». Poétique 24, 495-526.

KERMODE, F. (1967): The sense of an ending. Londres-NuevaYork: Oxford University Press.

Kotin Mortimer, A. (1985): La clôture narrative. París: José Corti.

KrISTEVA, J. (1978): Semiótica. Madrid: Fundamentos.

LÁzARo CARRETER, F. (1980): Estudios de lingüística. Barcelona: Crítica.

- (1990): De Poética y Poéticas. Madrid: Cátedra.

LOTMAN, I. (1970): «Le hors-texte». Change 6, 68-81.

- (1973): La structure du texte artistique. París: Gallimard.

MURPHY, J. (1985): La retórica en la Edad Media. México: FCE.

PASTOR Platero, E. (1993): "Algunas consideraciones sobre el epifonema en las Sonatas». En Escritura autobiográfica, J. Romera Castillo y otros (eds.), Madrid: Visor.

RASTIER, F. (1972): «Systématique des isotopies». En Essais desémiotique poétique, A. J. Greimas (ed.), 80-106. París: Larousse.

- (1987): Sémantique interpretative. París: PUF.

RIFFATERRE, M. (1971): Essais de stylistique structurelle. París: Flammarion.

SCHIAvo, L. (1980): Historia y novela en Valle-Inclán. Para leer «El Ruedo Ibérico». Madrid: Castalia.

SEgre, C. (1985): Principios de análisis del texto literario. Barcelona: Crítica.

SENABRE, R. (1987): Literatura y público. Madrid: Paraninfo.

SMith, B. H. (1968): Poetic closure. A study of how the poems end. Chicago: The University of Chicago Press.

SPERATTI-PiñERO, E. S. (1968): De «Sonata de Otoño» al esperpento. Londres: Tamesis Books.

SOBEJANO, G. (1988): «Culminación dramática de Valle-Inclán: El diálogo a gritos». En Estelas, laberintos, nuevas sendas, A. G. Loureiro (ed.), 111-136. Barcelona:Anthropos.

ZAMORA VICENTE, A. (1969): La realidad esperpéntica. Madrid: Gredos.

ZAVALA, I. (1990): La musa funambulesca. Madrid: Orígenes. 